\title{
Article
}

\section{How Do Observable Characteristics of Post-Mining Forests Affect Their Attractiveness for Recreation?}

\author{
Markéta Braun Kohlová, Petra Nepožitková and Jan Melichar *
}

Environment Centre, Charles University, 16200 Prague, Czech Republic; marketa.braun.kohlova@czp.cuni.cz (M.B.K.); petra.nepozitkova@czp.cuni.cz (P.N.)

* Correspondence: jan.melichar@czp.cuni.cz; Tel.: +420-220-199-464

\begin{abstract}
Afforestation is a popular practice of the recovery of landscape affected by open-cast coal mining. We investigated what impact the observable characteristics of restored forests have on their attractiveness for recreation framed as a one hour walk in a respective type of forest. In this study, we elaborate on some of the observable characteristics which have been previously found in the literature to affect the perceived attractiveness of outdoor environments. Environmental preference data were collected online using a quasi-representative sample of affected and control populations of the Czech Republic $(N=869)$. The questionnaire employed visual representations of typical reclaimed forest sites on spoil heaps in the Sokolov mining district. A mediation analysis revealed that forests growing in post-mining areas are perceived more negatively than the typical commercial spruce forest due to their lower permeability, lower level of stewardship, and perceived low safety. However, there are differences in observed characteristics also between different types of restored forests, even when controlling the effect of forest age. The results show for forestry practice that while some of the observed characteristics change by themselves with the increasing age of the forest (permeability, perceived safety, and naturalness of successional forests), improvement in others requires targeted after-care (perceived stewardship). In any case, our results are promising in that they imply that the recreational value of restored forests in post-mining areas may further increase in the future.
\end{abstract}

Keywords: reclamation; open-cast coal mine; environmental preference; recreation; attractiveness; observable characteristics; empirical survey; Czech Republic; photographs; mediation analysis

Academic Editors: Diane L. Haase,

Jeremiah R. Pinto and Owen

T. Burney

Received: 19 July 2021

Accepted: 25 August 2021

Published: 28 August 2021

Publisher's Note: MDPI stays neutral with regard to jurisdictional claims in published maps and institutional affiliations.

\section{Introduction}

Temperate forests are among the most aesthetically valued ecosystems and environments for recreation. In Han's study [1] comparing the attractiveness of six different biomes (coniferous forest, deciduous forest, desert, grassland, tropical forest, and tundra), forested biomes were perceived as very attractive, with coniferous and deciduous forests ranking much higher than grassland or desert. Quite a lot has been discovered about how its observable characteristics such as observed permeability, structural diversity, or perceived naturalness affect its attractiveness [2-4].

Nevertheless, in several forests planted and managed by people, it seems that care for the visual face of the forest has not yet become common practice. Typical examples are restored forests in areas that had been affected by previous open-cast coal mining activity. Understandably, other observable criteria and ecosystem functions such as geomorphological, hydric, and ecological balance [5] have priority, especially in the initial phase of a spoil heap's restoration. However, over time and at the moment of opening these forests to the public (for recreation), their visual appearance becomes of crucial importance. As Tyrväinen et al. [6] note, the quality of landscape and environment is one of the important elements for natural tourism. In the case of this study, natural tourism was centered around longer travel distances. According to these authors, the environmental preferences of people should be considered in forest planning and management. This is especially true 
in regions aiming at expanding their tourism carrying capacities [6], which is the case of many regions in the Czech Republic where coal mining has been terminated.

To provide a guideline for practitioners who are in charge of the management of human-made forests, we investigate how various observable characteristics of forests re/planted in post-mining areas affect their attractiveness. In this study, we focus on forests that were either replanted with a dominant tree species or spontaneously arose in the process of uncontrolled succession and consider three different growth stages of corresponding age classes (early stage between 10 and 15 years, middle stage between 15 and 35 years, and young stage between 35 and 55 years). Our research elaborates on previous knowledge about environmental preferences and extends its validity to the young stages of human-made and entirely natural outdoor environments.

Our findings are particularly relevant in the central European region (Czech Republic, Poland, East Germany) where large-scale open-cast mines and the spoil heaps in their vicinity were abundant and where re-/forestation has been one of the typical reclamation practices. According to Alves Dias et al. [7], there are 14 active open-cast coal mines extracting brown coal and lignite deposits in the Czech Republic (1 mine in the Sokolov basin and four mines in the North Bohemian basin), Poland (1 mine in the Bełchatów basin, one mine in the Turoszów basin and two mines in the Konin-Adamów basin), and East Germany (4 mines in the Lusatian area and three mines in the Central German area). In addition to the afforestation of post-mining areas for forestry use, extensive areas of degraded mining land are often transformed into agricultural land, artificial lakes, natural landscapes, and for recreation purposes, e.g., golf course, arboretum, bike park, water-based activities. We believe that our findings also relate to the reclamation of other human-made nature-like ecosystems, such as areas close to large road constructions.

\section{Environmental Preferences and Post-Mining Forests}

People often spend their leisure time in forested areas close to cities and towns and engage in recreational activities ranging from simply walking alone, with a family or dogs, outdoor exercising to hunting. However, not all forest areas are liked [8,9] and numerous observable characteristics have been identified to influence forest attractiveness [10]. Ode et al. [10] employed existing theoretical concepts of a landscape's visual character to create a nomenclature of characteristics and their measurable indicators. They identified coherence, perceived naturalness, disturbance, stewardship, complexity, imageability, historicity, ephemera, and visual scale as basic observable characteristics affecting landscape aesthetics [10]. Several visual indicators derived from these theory-based concepts have been investigated in empirical research $[5,9,11-14]$. Out of the structural attributes on the level of forest stands, the following affect the preference of visitors: size, volume, and structure of trees and undergrowth, species composition, and signs of forest management. People prefer tall/mature trees to short/young-stage trees, medium-level of the undergrowth, low level of shrubs, and absence of signs of soil preparation, e.g., [5,12,13,15-18]. A middle to higher variation in the size of trees is appreciated [12] together with some variation in tree spacing; trees situated in the foreground are appreciated rather than when placed in the background or being spread [14]. A medium-level tree density and ground vegetation are preferred [12,14]. A higher number of tree species and natural-looking features of the forest have positive impacts on peoples' preferences [12,13]. On the contrary, the size of clear-cuts, residues from both harvesting and thinning, and dead trees have a negative impact on preferences [12-14,16,18-20].

Even if the structural attributes of forests relatively consistently affect the preference in different countries, socio-demographic groups, and groups of people with different interests [15,17-19], the degree of these relations varies between different landscape settings, cultural contexts, and socio-demographic groups [12,21-23]. For example, the volume of large trees increases the preference for the forest more in men than in women [22]. Older women in Norway preferred grassland and heathland (compared to forests) more than other population groups [24]. Ribe [25] shows that people favoring resource production have lower 
standards of visual quality/scenic beauty than people favoring resource protection. Mean tree height affects the preference more in a group of forest owners than in a group of non-owners [22]. Different explanations exist for heterogeneity in preferences towards the same forest structures: the effect of familiarity on the environmental preference [11,24]; different underlying values besides the aesthetics such as ecological values, attitudes, and interests [25-27], background knowledge, and available information [16,19,25]. In effect, different factors of preference may be identified in studies conducted on different types of samples, such as experts in forestry, interested groups, and landowners, e.g., [14-16,25] or the general public, e.g., [16] and visitors, e.g., [13].

The visual characteristics evaluated in the current study represent general concepts of scenic beauty in a way they are perceived and interpreted by individuals rather than well-measurable physical attributes of the setting; see [12,15]. Hence, the general concepts may capture a mutual effect of several structural attributes such as the size of trees, extent of tree cover within the stand, and density of ground vegetation, the effect of which has been well-documented in the above-referred literature, e.g., [12,14,16,18].

In this research, we focused only on five general observable characteristics, namely, permeability, stewardship, perceived naturalness, safety, and familiarity. These features of forest appearance were selected as potentially relevant to post-mining forests, either as being typical for restored forests (such as a low level of permeability/prospect and stewardship) or being associated with mining activity and the subsequent restoration management (perceived naturalness, safety, and familiarity). The five features of the forests selected in the current study were most frequently observed and spontaneously evaluated by respondents in a small-scale qualitative pilot study that preceded the survey $(N=18)$. The additional features identified in the literature [10] were either not verbalized (such as coherence or imageability) or not relevant (e.g., ephemera) for the current study. A low level of permeability has been previously found to be associated with low restorativeness [9], which in turn decreases the environmental preference [28]. Gatersleben and Andrews [9] found that natural environments with a higher level of prospect (clear field of vision) and lower level of refuge are more restorative than environments with a lower prospect and high refuge. The positive impact of an open view has been corroborated by yet other authors, e.g., $[12,13,24]$. Their findings imply that less permeable and potentially dangerous environments demand more attention, lead to a lower restorative potential, and may be, therefore, less preferred.

Additionally, stewardship in terms of visible signs of human care and land use affects peoples' preferences [29]. However, the direction of the effect of stewardship on preference is not clear. While people prefer forests close to the natural state and with a low level of stewardship, they also like the results of forest management which improve the aesthetic quality of a forest allowing for a clearer view [15] such as the removal of deadwood and cuttings.

For recreation, more natural environments that appear more natural to the observers are generally preferred, even if the perceived naturalness may not correspond to the ecological natural state as a result of the process of uncontrolled succession. In addition, perceived closeness to the natural state may be based on the state of the ecosystem and landscape management [30]. For instance, in protected areas, careful management may be often conducted to increase ecological naturalness. According to Hoyle et al. [11], there is a positive association between the perceived naturalness and planting structure. In their study, they discovered that landscapes with intermediate levels of management were perceived as more natural than strongly natural landscapes in terms of ecological naturalness. Their research uncovered a significant but weak relationship between ecological naturalness and aesthetic perception. Landscapes with moderate to higher levels of succession were preferred more [11]. Importantly, for this research, perceived naturalness is influenced by culture and history. Naturalness is perceived through the lens of the traditional local landscape, land use, and cultural patterns [10], which, in the Czech Republic, much of the landscape is shaped by commercial timber forests with a spruce monoculture. Which is 
one of the reasons why the spruce even-aged forest is considered as a reference forest in this study. Naturalness, unless otherwise indicated, is further understood as a perceived naturalness that appears natural to observers.

Some natural environments are not perceived to be safe and invoke a sense of fear. In their research about the attractiveness of urban green spaces, Lis et al. [31] discovered that perceived danger is affected by perceived path use and concealment. The number of shrubs has a clear effect on perceived danger because large shrubs could easily hide dangerous people or animals. Desolate landscapes with signs of low use often lead to a sense of danger. Chiang et al. [32] discovered that a high level of visibility is associated with perceived safety and that an increase in threat combined with an increase in exploration yielded an increase in preferences. Chiang et al. [32] uses this example to argue that in some cases, negative feelings for the environment may later transform into positive feelings, such as fear turning into a positive emotional response. In their research about forested urban areas, Sonti et al. [33] uncovered some reasons why people may perceive forest areas as dangerous. One of the main reasons for not visiting urban forests is fear for safety, where women may fear for their safety and men are worried about the safety of women. People are afraid of drug addicts and drunk people in the area. Another source of worry may be natural dangers, such as becoming lost in the forest or running into rats or insects. Some of Sonti's et al. [33] interviewees voiced a clear dislike of the perceived dirtiness of natural areas.

The last characteristic which affects the attractiveness of outdoor environments and which may be relevant for post-mining forests is familiarity [29,34]. Familiarity with an environment has been shown to affect environmental preference in the same direction [29,34-36], but also evidence to the opposite exists. Participants in studies by Svobodova et al. [5] and by Arnberger and Eder [29] preferred other environments than those in which they grew up. Of note is that Svobodova et al. [5] investigated the environmental preferences of people living in post-mining regions where familiarity relates to a restored forest, as in this research.

\section{Research Goals}

This study aims to explore the effect of specific observable characteristics of postmining restored forests on their attractiveness for recreation defined as a one hour walk in a respective type of restored forest. To test the first hypothesis, a typical commercial spruce forest was chosen as the reference forest for comparison with post-mining restored forests. The reference forest represents an intensively managed monoculture plantation of Norway spruce (Picea abies), which occupies almost 50\% of the Czech forest land. The reference forest is considered as even-aged and its age was set approximately at 75 years because the age class between 60 and 100 years occupies about 30\% of the forest land [37].

On data collected in an online survey on a sample of the Czech adult population, we test the following predictions:

1. Post-mining restored forests are less attractive for recreation than commercial timber forests not affected by land disturbance of mining activities;

2. Post-mining forests (considered as any type of reforested forest disregarding their age and restoration process), as well as their individual types (with regard to their growth stage and restoration procedure) differ in their attractiveness due to their different visual character in terms of permeability, perceived naturalness, safety, stewardship, and familiarity;

3. Lower levels of perceived naturalness, safety, permeability, and stewardship and a higher level of perceived familiarity account for a lower attractiveness of post-mining forests, young stage forests, and replanted forests. 


\section{Materials and Methods}

\subsection{Study Site}

The study site is located at the Sokolov spoil heaps in the Sokolov brown-coal mining district, which is in the western part of the Czech Republic. The spoil heaps began to be formed in the 1960s with the substrate composed of tertiary clays (so-called cypris formation). The substrate consists mostly of kaolinite, illite, and montmorillonite and is impregnated by siderite and calcite. The spoil heaps have different sizes, mostly up to $5 \mathrm{~km}$ and a height up to $200 \mathrm{~m}$ above the original terrain. The spoil heaps are mostly covered by a mosaic of restored forest stands, either as replanted forests or unreclaimed sites dedicated to spontaneous succession. Restored forest stands are even-aged and consist of one or several different tree species. The terrain of replanted forest sites had been leveled before tree planting, compared to which, the surface of unreclaimed sites consists of a parallel series of waves up to $2 \mathrm{~m}$ high formed by heaping machinery when overburden was deposited during technical reclamation [38].

Reclaimed plantations are mostly dominated by one tree species, or two tree species of one genus combined. Usually, Scots pine (Pinus sylvestris), Black pine (Pinus nigra), lodgepole pine (Pinus contorta), Norway spruce (Picea abies), Serbian spruce (Picea omorika), common alder (Alnus glutinosa), grey alder (Alnus incana), common oak (Quercus robur), and small-leaved lime (Tilia cordata) were used for replanting. Forest stands created by spontaneous succession on unreclaimed sites are dominated mostly by silver birch (Betula pendula) and goat willow (Salix caprea) [39].

The re-establishment of forest stands in the post-mining area of the Sokolov browncoal mining district began on the spoil heaps in the late 1960s and continues to the present. Replanted forests are typically middle and young-aged forests, with a height from 1.5 to $10 \mathrm{~m}$ (10-30 years old), or above $10 \mathrm{~m}$ (30-55 years old), respectively. Open-cast brown coal mining still continues at the open-cast mine Jiř́. The mine is expected to be closed in 2038. Therefore, reclamation activities, including forest restoration, will continue for at least 4 decades.

The spoil heaps are located in the immediate vicinity of the towns Sokolov (approximately 23,000 inhabitants), Chodov (13,000 inhabitants), a Nové Sedlo (2,600 inhabitants), and 14 smaller municipalities with a total of 53,800 inhabitants, which accounts for $61 \%$ of the total population of the Sokolov District.

\subsection{Participants}

An online questionnaire survey (see the transcript of the main items of the questionnaire available in Appendix A) was administered to a sample of Czech adults $(N=869)$ consisting of a population from the respective region $(N=629)$ and a control (unaffected) population from the Central Bohemia region $(N=240)$. Quotas for age, gender, and education were used to represent the socio-demographic structure of both regions. The quotas used for the sampling were general socio-demographic characteristics that are commonly used for quasi-representative samples of the population [40]. At the same time, region, age, gender, and education of people have been found to explain differences in environmental preference, e.g., $[12,22,24]$ and, hence, might have been confounding variables in the model.

As a result, over half of the participants were women $(N=475)$. The median age of participants was 42 . The youngest participant was eighteen and the oldest 65 . The vast majority of our respondents reached either vocational $(N=345)$ or high school education $(N=319)$.

A step-wise method was used to recruit the respondents for the study. In the first step, respondents were recruited from a participant panel of an opinion poll company using quota sampling. The quotas for age, gender, education level, and residence were constructed so that the sample resembled the adult population (18+) of the affected regions, i.e., Karlovy Vary, and the control Central Bohemian region. As some of the predefined quotas were not filled in the first step (especially groups of people with low education levels and from the Karlovy Vary region) personal visits at homes were conducted in the 
second step. This way we recruited additional respondents $(N=96)$. The resulting sample well represented the population of the affected region of Karlovy Vary and the control region of Central Bohemia. For the details of the sample structure, see Table 1.

Table 1. Demographic and sampling structure of the sample, $N=869$.

\begin{tabular}{ccc}
\hline $\begin{array}{c}\text { Demographic and Sampling } \\
\text { Characteristic }\end{array}$ & Number of Obs. & Relative Frequencies \\
\hline Male & 394 & $45.34 \%$ \\
Female & 475 & $54.66 \%$ \\
\hline Elementary education & 45 & $5.18 \%$ \\
Vocational and secondary education & 345 & $39.70 \%$ \\
High school education & 319 & $36.71 \%$ \\
University education & 160 & $18.41 \%$ \\
\hline First sampling & 773 & $88.95 \%$ \\
Second sampling & 96 & $11.05 \%$ \\
\hline
\end{tabular}

The survey was conducted in 2016; participants were remunerated for participation in the survey.

\subsection{Materials}

\subsubsection{Visual Stimuli of Evaluated Forests}

The electronic questionnaire contained photographs of six forest stands, five of them represented typical outcomes of the forest restoration process at the Sokolov spoil heaps and one represented a reference forest stand from the vicinity of spoil heaps not affected by mining (mature spruce monoculture). More specifically, every forest stand was represented by a quartet of photographs displayed at the same time on the slide used for evaluation of the observed characteristic and the attractiveness of the forest in the questionnaire (see the questionnaire in Appendix A). Altogether, 24 photographs were shown to every participant in the survey. Photographs of the recovered forests were taken at selected Sokolov spoil heaps, specifically at Podkrušnohorská heap, Smolnická heap, and Antonín heap. Photographs of the reference forest stand (Picea abies) were taken in the nearby Libavské valley located in the same region.

In total, six types of forest stands were selected for this study. Illustrative photos with additional information about forest management characteristics of the evaluated forests (not presented to participants in the questionnaire) are shown in Figure 1.

Five forests represented various types of forest restorations, including both restoration practices-replantation and spontaneous succession-and different growth stages of forest stand. Specifically, pine replantation and alder replantation of the middle growth stage at the age of 35 years were chosen as the most represented types of reclaimed plantations with one dominant tree species. Alder-reclaimed plantation is dominated by Alnus glutinosa and Alnus incana and the species composition of the alder forest stand is relatively poor. Pine reclamation is represented by plantation of Pinus sylvestris and because the pine stands are overgrown, they are vulnerable to abiotic and biotic stressors.

Three forest sites with spontaneous succession were selected as representatives of the second restoration practice on unreclaimed sites and corresponded to three growth stages - the early growth stage at the age of 15 years, middle growth stage at the age of 35 years, and young growth stage at the age of 55 years-to evaluate the change of observable characteristics with the increasing age of the forest. Succession stands in the early and young growth stage are dominated by Betula pendula and succession in the middle growth stage is represented by Salix caprea. Species diversity is relatively low for the early growth stage of succession, but older growth stages are characterized by an increase in species diversity. 

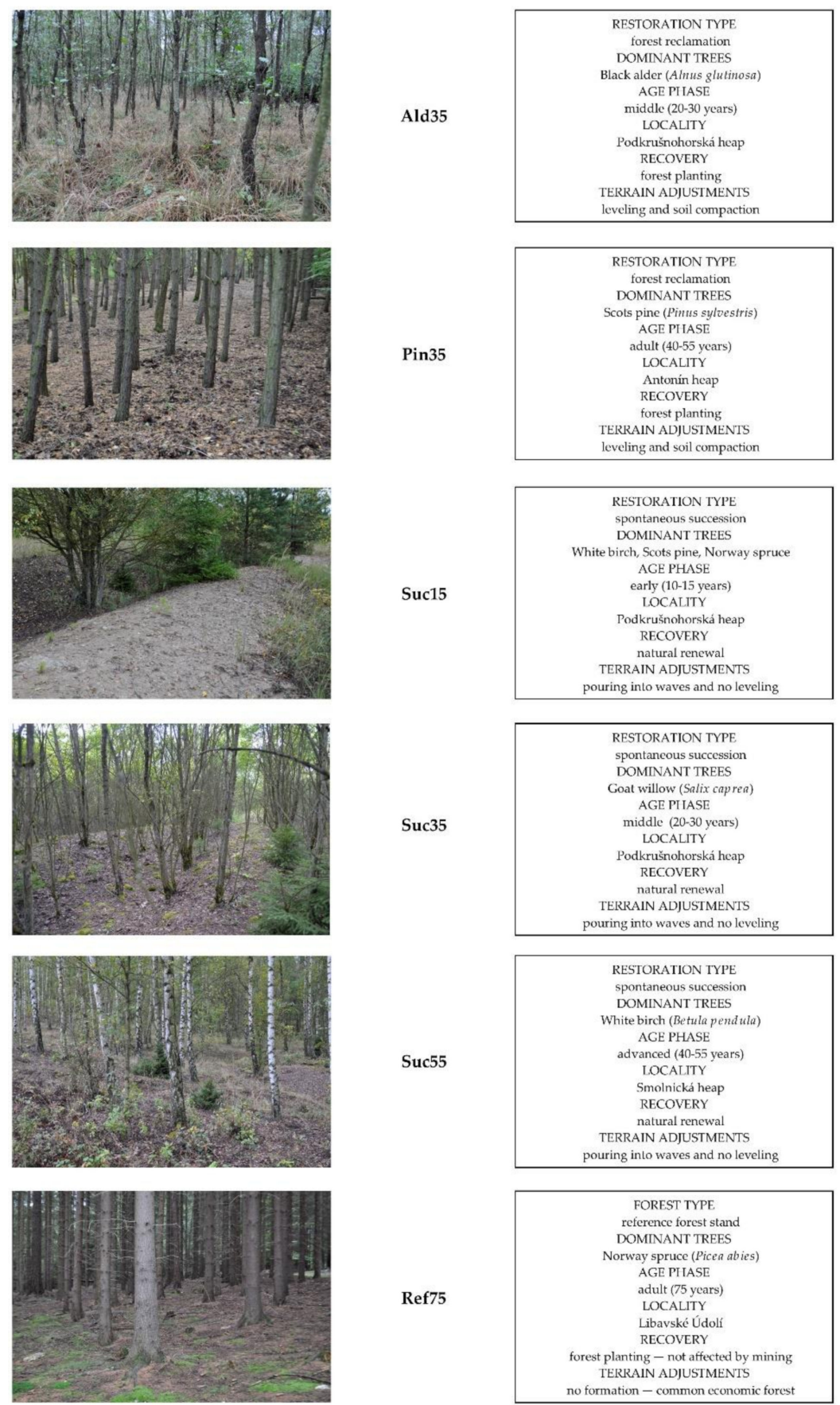

Figure 1. Illustrative photos with additional forest management characteristics of the evaluated forest stands. Note: Note that only the photographs not the additional characteristics were presented to participants in the questionnaire.

Conifer monoculture with one dominant tree species, Norway spruce (Picea abies), at the mature growth stage at the age of 75 years was chosen as a reference forest. It is not affected by open-cast coal mining and represents the most typical type of forest used for recreation in the Sokolov District. However, this type of forest ecosystem is characterized by low species diversity.

Three different 35-year-old, restored forests were included in the set to allow for comparison of restoration practices (see the results for model 2 below). Thirty-five years is the minimum age for opening forests to the public because, until then, the terrain is unstable after logging. Only one forest type aged at 55 years was included in the set of photographs because such old, restored forests are still few in the Czech Republic. There 
was a significant limitation to our photographs. Since the reclamation process started less than sixty years ago, the vegetation in the photographs is not representative of all possible reclamation forests and is not in age levels comparable to common recreational forests, i.e., 75 years.

Colored photographs were taken during the summer of 2016. Since photography took place in the summer, the vegetation was lush and trees were easy to identify. In our case, photographs simulated the environment for a walk through the forest, capturing the trees from proximity and, thus, allowing better perception of the details such as the distance of the trunks, wing density, undergrowth, etc. We used the same scale in the photographs to allow for comparison [10]. Each type of forest was represented by four photographs, to show the natural diversity of the stand.

\subsubsection{Measures of Forest Types, Observable Characteristics, and Attractiveness}

Post-mining forest. For the purpose of comparison, a variable post-mining forest (Post-mining) was created. The variable had a value of 1 for any type of restored forests (disregarding their age or whether they were planted or formed by spontaneous succession), and a value of 0 for the reference forest.

Forest type. Six dummy variables were created to indicate the evaluated type of forest. The variables were as follows:

- $\quad$ Ald35-re-planted alder forest, 35 years old;

- $\quad$ Pin35-re-planted pine forest, 35 years old;

- Suc15-spontaneous succession forest, 15 years old;

- Suc35-spontaneous succession forest, 35 years old;

- Suc55-spontaneous succession forest, 55 years old;

- Ref75-commercial spruce timber forest, 75 years old.

Attractiveness. To measure attractiveness, participants indicated how tempting for recreation are the forests displayed in the photographs. Attractiveness was measured by a one-item question asking: "How tempting would it be for you to walk on a forest way in this forest for one hour?" The responses were measured on a 5-point Likert-type scale ranging from $-2=$ not at all to $2=$ very tempting.

Observable characteristics. Perception of forests in terms of their observable characteristics was evaluated with a battery of five items that captured permeability, stewardship, perceived naturalness, safety, and familiarity. The wording of the observed characteristics evaluated in the current study was adapted to the vocabulary used by respondents in the pilot study. Perception of observable characteristics was measured on 5-point Likert-type scales ranging from -2 to +2 with the following endpoints: not permeable-permeable, unnatural-natural, not maintained at all-maintained, unfamiliar to me-familiar to me, dangerous-safe. For details of variables used in the analysis see Table 2 and the transcript of the main items of the questionnaire is available in Appendix A.

\subsection{Design and Procedure}

Respondents approached the questionnaire online. In Part 1, participants were shown eight photographs showing various types of forest (see for the illustration Appendix A). They could observe them as long as they wanted. Further, in Part 1, participants evaluated 6 types of forest stands - each forest was always represented by four photographs-in terms of their observable characteristics. In the evaluation, the forests were ordered to participants randomly. Afterward, in Part 2, participants evaluated the attractiveness of the forests for recreation; again the forests were displayed in the same order as in Part 1. Part 3 consisted of a discrete choice experiment, in which additional forests were evaluated (not reported in the present study; for details see [8]). In the last part, participants were debriefed and asked about their socio-demographics. 
Table 2. Description of variables, $N=869$.

\begin{tabular}{ccc}
\hline Variable name & Type & Values \\
\hline Attractiveness & Ordinal & $-2=$ not at all-+2 $=$ very tempting \\
Permeability & Ordinal & $-2=$ not permeable $-+2=$ permeable \\
Naturalness & Ordinal & $-2=$ unnatural $-+2=$ natural \\
Stewardship & Ordinal & $-2=$ not maintained at all $-+2=$ maintained \\
Familiarity & Ordinal & $-2=$ unfamiliar $-+2=$ familiar \\
Safety & Ordinal & $-2=$ dangerous $-+2=$ safe \\
Post-mining & Dummy & $1=$ post - mining forest, $0=$ else \\
Ald35 & Dummy & $1=$ alder plantation, 35 years old $0=$ else \\
Pin35 & Dummy & $1=$ pine plantation, 35 years old, $0=$ else \\
Suc15 & Dummy & $1=$ succession forest, 15 years old, $0=$ else \\
Suc35 & Dummy & $1=$ succession forest, 35 years old, $0=$ else \\
Suc55 & Dummy & $1=$ succession forest, 55 years old, $0=$ else \\
Ref75 & Dummy & $1=$ reference spruce forest, 75 years old, $0=$ else \\
\hline
\end{tabular}

\subsection{Analysis}

To test the effects of forest types on their attractiveness for recreation mediated by their observable characteristics, a structural modeling approach (SEM) with partial mediation analysis was used [41-44]. SEM is commonly performed in social-science research to explore complex relationships between concepts and both direct and indirect effects. Mediation analysis has been used in numerous studies in environmental behavior and appraisal $[31,45,46]$. In the current analysis, a structure with five observable characteristics as parallel mediators of the relationship between the type of forest and its attractiveness for recreation was tested. Three separate models (see Figures 2-4 for graphical representation of the model) were estimated to explain: (i) the generally lower attractiveness of post-mining forests compared to commercial timber forest (model 1); (ii) differences in attractiveness between same-age forests restored in three different ways (model 2); and (iii) the change in the attractiveness of spontaneous successional forest with age (model 3). In the models, the mediators were allowed to correlate. Diagonally weighted least squares estimator and bootstrapping were used in fitting the models.

We used Stata and R software to analyze the data that are available in Supplementary Materials (Table S1). In R 4.0.2, we used the lavaan package [42] to build and estimate SEM.

\section{Results}

\subsection{The Effect of Observed Characteristics on the Attractiveness of Post-Mining Forests}

An ordinal logistic model corroborated the original expectation that post-mining forests are much less attractive than the reference commercial spruce timber forest, $B=-1.53$, $O R=0.21,95 \%$ CI $(-1.68,-1.39), z=-21.39, p<0.001 ; B$ denotes the unstandardized regression coefficient and $O R$ denotes the odds ratio in the ordered logit model, CI are $95 \%$ confidence intervals for $B, z$ is the test statistic for the test of $B$ and $p$ is $p$-value for $z$-test. Model one revealed that post-mining forests were perceived as less attractive than the reference forest and that the lower attractiveness was affected by the observed characteristics; the indirect effect of post-mining was negative $(\beta=-0.293)$ and statistically significant $(p<0.001) ; \beta$ denotes standardized regression coefficients of a fitted structural equation model and $p$ corresponds to $p$-values of $z$-test. After accounting for the indirect effect of the observed characteristics, the effect of the post-mining forest significantly decreased (total effect, $\beta=-0.339, p<0.001$ and the direct effect, $\beta=-0.047, p<0.05$ ).

From the individual observed characteristics, permeability had the strongest indirect effect on attractiveness $(\beta=-0.094, p<0.001)$, followed by safety $(\beta=-0.073, p<0.001)$, and familiarity $(\beta=-0.068, p<0.001)$. The indirect effect of naturalness was not statistically significant. Regression coefficients on the left-hand side of model one showed that postmining forests differed from commercial timber forests in particular in terms of low levels of permeability $(\beta=-0.428, p<0.001)$, stewardship $(\beta=-0.425, p<0.001)$, and safety $(\beta=-0.319$, $p<0.001)$. Post-mining forests were not perceived as being different in naturalness; the 
effect of post-mining forests on naturalness was not statistically significant. Post-mining forests were less familiar to people than commercial timber forests (see Figure 2 for details). The effects of all the observed characteristics on the attractiveness of the forest for recreation were positive and statistically significant.

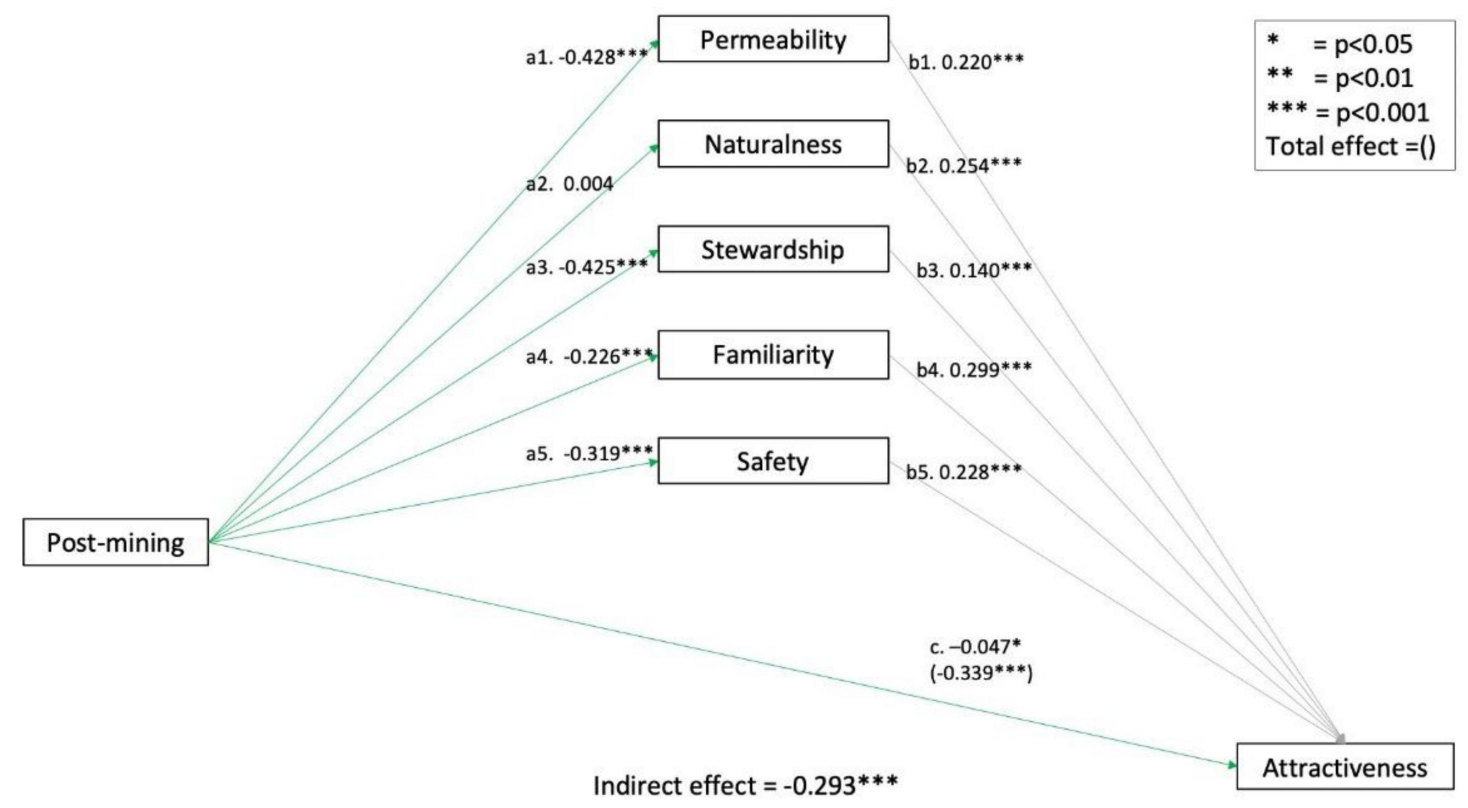

Figure 2. Mediation by observed characteristics of the effect of post-mining forests on attractiveness (model 1). Note: Post-mining is a dummy variable coded as 1 for all types of post-mining forests and 0 for the reference commercial timber forest. The coefficient $c$ denotes the direct effect and the coefficient in parentheses the total effect of forest type. The regression coefficients $a$ refer to the effect of the independent variable on the mediator variables and the regression coefficients $b$ refer to the effect of the mediator variables on the dependent variable.

\subsection{The Effect of Observed Characteristics on the Attractiveness of Different Types of Restored Forests}

The effect of different reclamation practices on the visual character of the forests and their attractiveness at the age of 35 years were tested in model 2. The replanted alder forest (Ald35) and spontaneous successional forest (Suc35) were compared to the replanted pine forest (Pin35) that was kept as the reference category in the model. Model two revealed that observed characteristics largely accounted for the differing attractiveness of forests created through different restoration practices. However, no systematic difference was visible in the age of 35 years between re-planted and spontaneously growing successional forests. Both total effects of Ald35 vs. Pin35 $(\beta=-0.474, p<0.001)$ and Suc35 vs. Pin35 were negative, but the latter was much smaller $(\beta=-0.071, p<0.001)$. It showed that the pine forest was the most attractive, followed by the successional, and then the alder forest. Additionally, both indirect effects, which captured the mediation by observed characteristics, were negative and statistically significant (for Ald35, $\beta=-0.271, p<0.001$, for Suc35, $\beta=-0.075, p<0.001)$. The larger negative effect of Ald35 than of Suc35 indicated that this type of restoration yielded significantly visually inferior forests than spontaneous succession. This finding was further corroborated by the large negative effects of Ald35 on the observed characteristics, namely, on permeability $(\beta=-0.646, p<0.001)$, stewardship $(\beta=-0.561, p<0.001)$, safety $(\beta=-0.445, p<0.001)$, and familiarity $(\beta=-0.183, p<0.001)$. From the point of view of naturalness, Ald35 was, on the contrary, perceived positively $(\beta=0.126, p<0.001)$.

The spontaneous successional forest was inferior to the pine reclaimed forest in all observed characteristics except for naturalness, but the effects were smaller than those of Ald35; specifically for familiarity $(\beta=-0.137, p<0.001)$, permeability $(\beta=-0.132, p<0.001)$, and safety $(\beta=-0.060, p<0.01)$. Interestingly, the successional forest was perceived as being 
less natural than both reclaimed forests $\operatorname{Pin} 35(\beta=-0.062, p<0.05)$ and Ald35-admittedly, due to visible wave-like terrain unevenness created by the dumping of overburden material typical for this growth stage. Concerning stewardship, Suc35 did not significantly differ from Pin35 ( $\beta=-0.005, p>0.05)$. See Figure 3 for more details.

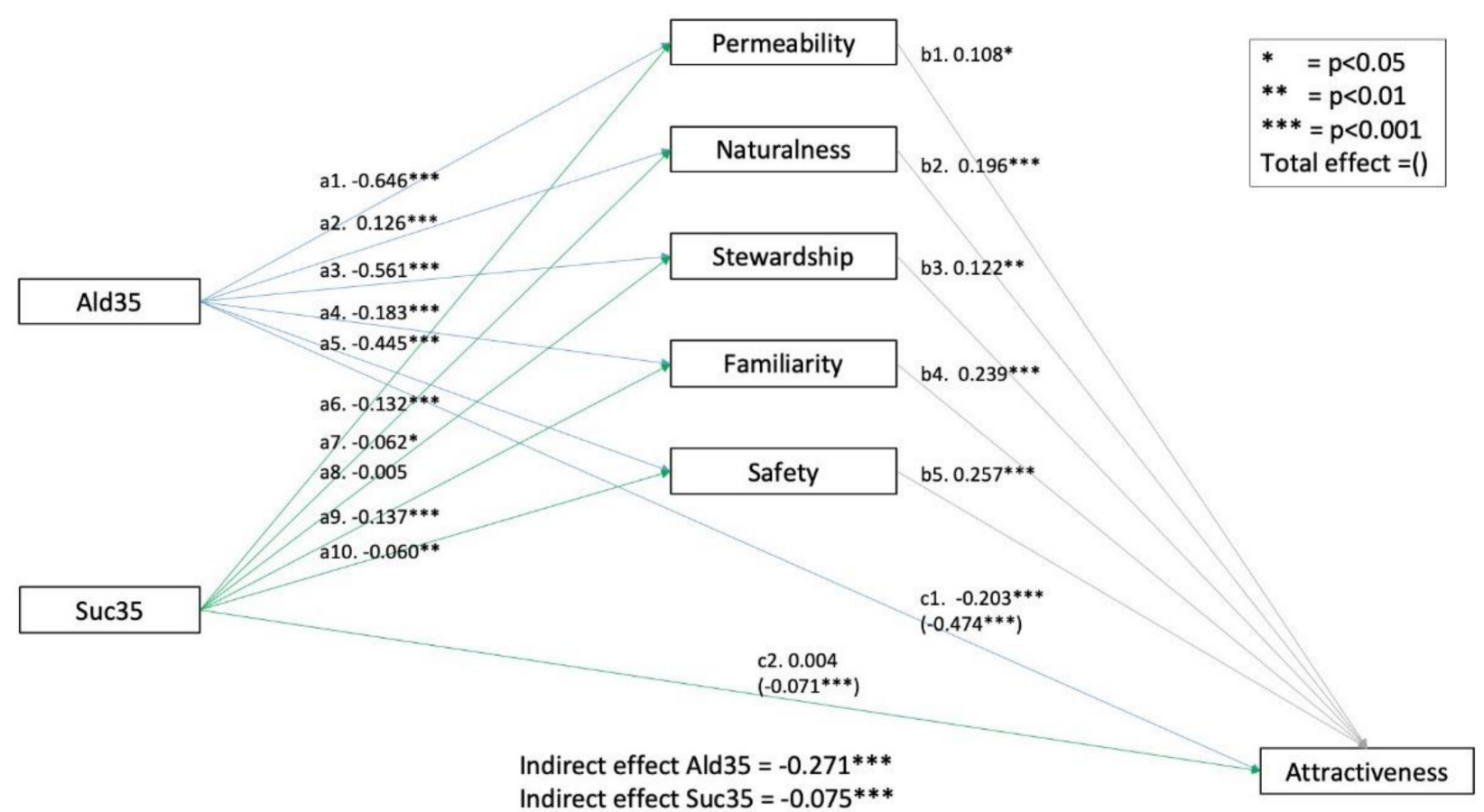

Figure 3. Mediation by observed characteristics of the effect of alder restoration and succession on attractiveness (model 2). Note: Ald35 is a dummy variable coded as 1 for alder reforestation and 0 for pine reforestation. Suc35 is a dummy variable coded as 1 for spontaneous succession and 0 for pine reforestation. The coefficients $c$ denote the direct effects and the coefficients in parentheses the total effects of forest types. The regression coefficients $a$ refer to the effect of the independent variable on the mediator variables and the regression coefficients $b$ refer to the effect of the mediator variables on the dependent variable.

\subsection{The Effect of Observed Characteristics on the Attractiveness of Different Growth Stages of Successional Forest}

The effect of age, at the growth stages of 15, 35, and 55 years, of the spontaneous successional forest on attractiveness and mediation of the effect by observed characteristics was tested in model 3. The middle-age category Suc35 was held as the reference category. The total negative effect of Suc15 $(\beta=-0.152, p<0.001)$ and the total positive effect of Suc55 $(\beta=0.134, p<0.001)$ revealed that the attractiveness of the spontaneous successional forest increased with time. Both positive and statistically significant indirect effects indicated that the improving visual character of the forest mediated the effect of age on the attractiveness of the successional forest (for Suc55, $\beta=0.187, p<0.001$, for Suc15, $\beta=-0.062, p<0.05$ ). After accounting for the mediators, both direct effects decreased significantly and the direct effect of Suc55 was no longer statistically significant $(\beta=-0.052, p>0.05)$.

A larger indirect effect of Suc55 than of Suc15 together with generally larger effects of the age on observed characteristics for Suc55 than for Suc15 indicated that the visual character of the successional forest changed more in the higher growth stage, i.e., between 35 and 55 years, than in the lower growth stage, i.e., between 15 and 35 years. Between 35 and 55 years of age, the successional forest improved in particular in terms of permeability $(\beta=0.264, p<0.001)$ and safety $(\beta=0.185, p<0.001)$; notice that respective effects were not statistically significant for Suc15. On the contrary, concerning stewardship, the successional forest gained more between 15 and 35 years (for Suc15, $\beta=-0.239, p<0.001$ ) than between 35 and 55 years, where the effect was statistically insignificant (for Suc55, $\beta=-0.039$, $p>0.05$ ). In terms of naturalness, the successional forest improved both between 15 and 
35 years (Suc15, $\beta=-0.120, p<0.001)$,) and between 35 and 55 years $(\beta=0.172, p<0.001)$. Rather surprisingly, familiarity decreased in the early stage (Suc15, $\beta=0.096, p<0.01$ ) and increased again in the young stage (Suc55, $\beta=0.222, p<0.001$ ). To sum up, model three corroborated previous findings that observed characteristics of post-mining forests account for different levels of their attractiveness for recreation. The analysis also revealed that some of these observed characteristics spontaneously improved after time, making older post-mining forests more attractive than younger forests. See Figure 4 for more details.

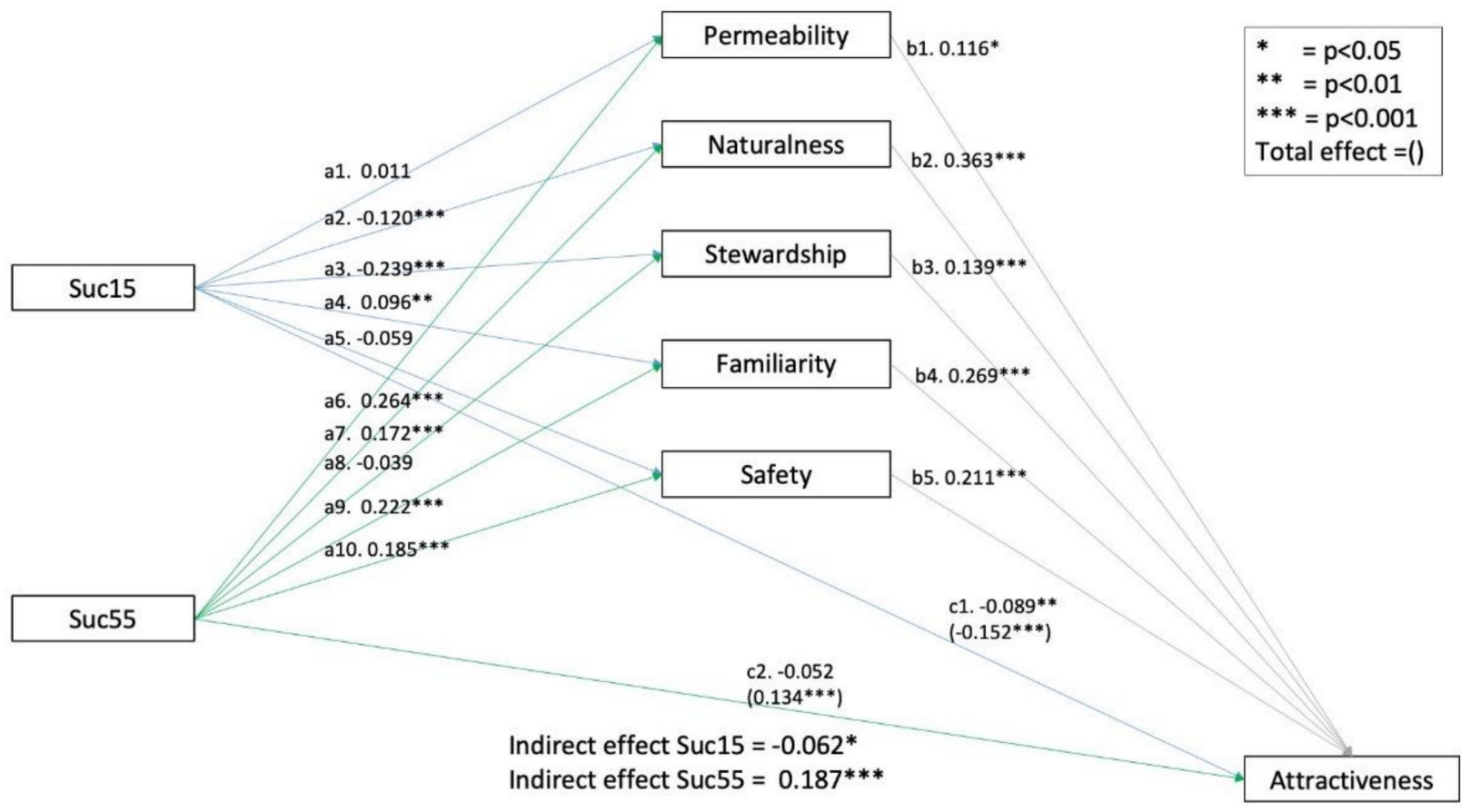

Figure 4. Mediation by observed characteristics of the effect of age of spontaneous successional forest on the attractiveness (model 3). Note: Suc15 is a dummy variable coded as 1 for successional forest at the age of 15 years and 0 for successional forest at the age of 35 years. Suc55 is a dummy variable coded as 1 for successional forest at the age of 55 years and 0 for successional forest at the age of 35 years. The coefficients $c$ denote the direct effects and the coefficients in parentheses the total effects of successional forest age. The regression coefficients $a$ refer to the effect of the independent variable on the mediator variables and the regression coefficients $b$ refer to the effect of the mediator variables on the dependent variable.

\section{Discussion}

Following previous findings [5,8], the results corroborated that restored forests in the Sokolov post-mining areas with terminated open-cast coal-mining activity were less attractive for recreation than conventional commercial spruce timber forests. Different observed characteristics of restored forests, partly regardless of the chosen restoration procedure, accounted for the lower attractiveness of post-mining forests for recreation. The restored forests (and, hence, the forests evaluated in this study) owed their observable characteristics such as a low level of permeability, stewardship, or safety to their relatively low age. Of note is that the re-establishment of forest ecosystems on the Sokolov spoil heaps had a relatively short-term history. Restored forest stands were typically in the early, middle, and young growth stages, as the first technical reclamation and afforestation of spoil heaps began at the turn of the 1970s and 1980s, while most managed forests in the vicinity of mining sites were in the mature growth stage.

Neglecting the effect of the growth stage of forests on attractiveness for recreation, we were interested in what extent the attractiveness of forests currently existing as a result of various restoration processes was explicable by their observable characteristics. Besides the effects of observable characteristics of different reclamation practices (at the same growth stage), we were interested in how the observable characteristics-responsible for attractiveness-changed with growth stages of spontaneous succession. 
The results of the present study clearly indicated that all examined observable characteristics, regardless of the type of reforestation method and tree species, affected the attractiveness of the forest for recreation in the Sokolov post-mining areas. In line with previous findings, e.g., [2], perceived naturalness was one of the important factors constituting the environment's attractiveness, even if the perception of the environment as natural in terms of ecological naturalness may not have corresponded to its origin or the reforestation method. With respect to previous evidence [11,30], it is not so surprising that perceived naturalness did not mediate the effect of post-mining forests on their attractiveness (compared to the reference commercial forest). When comparing different reforestation methods of 35-year-old forests, particularly spontaneous succession (with the predominance of Salix caprea) and two types of planted forests (Alnus glutinosa and Pinus sylvestris), perceived naturalness partially affected forest attractiveness. Yet, the planted alder forest was perceived to be the most natural, and the forest born out of spontaneous succession was perceived to be the least natural. On top of this, in the case of spontaneously growing successional forests, perceived naturalness, and so attractiveness grew with the forest age, which implied that older forests tended to be perceived as more natural than younger forests. This finding can be explained by the fact that perceived naturalness is conceptually different from the ecological state of the nature of the ecosystem and may relate more to the appearance of the forest that people know from popular recreation areas than the appearance of unmanaged forests.

Another characteristic responsible for the relatively low visual attractivity of restored forests was their low permeability. The truth is that walking in nature-like habitats with a low permeability may not be restorative [9]. Compared with conventionally managed commercial forests, a low permeability has a strong negative influence on the attractiveness of restored forests. Both in the case of the planted alder forest and spontaneous succession of Salix caprea, low attractivity could be explained by the low level of permeability. There was no difference in the perceived permeability of the first two phases of succession; however, it gained prominence when comparing 35- and 55-year-old successional forests.

The effect of perceived stewardship on attractivity was similar to the effect of permeability. However, there were slight differences. As the literature shows [15,29], people prefer a medium level of stewardship in natural habitats. Deadwood left behind or lack of trimness of the forest stand (neglected pruning) decreases forest attractivity [15]. Following this evidence, our structural equation models showed that perceived stewardship had a positive effect on the attractiveness of post-mining forests. Forest stewardship, as well as permeability, were much lower in restored forests (Post-mining) than in commercial timber forests; hence, influencing its (lower) recreational attractiveness. Forest reclamation with alder plantation was perceived to be not well-maintained and, therefore, less attractive. On the other hand, succession with Salix caprea was perceived to have the same level of stewardship as the forest reclamation with Pinus sylvestris. With the change of forest age from 15 to 35 , the perceived stewardship of the spontaneously growing successional forest increased, and so did attractiveness. A change to age 55 did not result in any significant change.

Familiarity was another factor positively influencing the attractiveness of forests for recreation. This finding also corresponded to the results of previous studies [5,34]. Their results $[5,29]$ pinpoint the fact that people living in locations damaged by mining tend to perceive the attractiveness of some types of native post-mining forests more critically than people not living in mining-influenced areas [8]. This is especially true for forests whose attractiveness is similar to conventional recreational forests, e.g., pine reclamations [8]. Local people living in the vicinity of spoil heaps in the Sokolov District are less familiar with restored forests (Post-mining) than with conventional forests, and this makes them less attractive. On top of this, people are even less familiar with reclaimed alder forests and forest types born out of spontaneous succession and, thus, they are perceived to be less attractive. Surprisingly, it is not true that familiarity continuously increases with the age of successional forests; people perceived earlier phases of succession as more familiar than 
medium-age successional forests, and the oldest forests (55 years) were perceived as the most familiar.

Safety was another factor influencing the attractiveness of post-mining forests for recreation, as proven by other studies [31,33]. Post-mining forests in the Sokolov District were clearly perceived to be less safe than commercial timber forests. From the selected restored forest types, pine reclamation was perceived as the most secure. The safety of alder was negatively influenced by a thick herbaceous vegetation and shrub layer [31]; succession showed visible terrain deformations caused by the dumping of overburdened material into 1-2 $\mathrm{m}$ high waves. From the safety perspective, the evaluation of the highest growth stage of succession (Betula pendula) was more positive than the middle or early growth stage (Salix forests).

To sum up, indirect effects were statistically significant in all the models and total effects decreased (beyond the limit of statistical significance in half of the models) which implies that the inclusion of observable characteristics into the explanation of attractiveness of different types of post-mining forests is justified. However, the significant direct effects imply that additional observable characteristics beyond those included in the current study explain variability in the attractiveness of forests. One may consider including complexity (diversity and richness of forest features) and coherence (harmony of forest components) $[2,4,47]$ into the models as these may reflect physio-morphological features (such as the shape and the slope of the terrain) and other environmental characteristics such as vegetation composition (the horizontal and vertical structure of the plant community).

The results of the current study corroborated previous findings that certain types of nature-like environments are not attractive for recreation as they evoke potential danger $[9,34]$ and that restored post-mining forests may be a typical example. With respect to the visual character of post-mining forests, this study provided additional evidence for the prospect-refuge theory [34].

Admittedly, cultural aspects of environmental preference that could refine knowledge concerning the attractiveness of restored forests and the perception of the visual character relating to the experience of people living in post-mining environments were not explored in the current study. We believe that people's experience with post-mining environments deserves attention in future research.

The findings of the study implicated that in the current growth stage, the attractiveness of forest restorations for recreation in the Sokolov post-mining areas is low compared to traditionally managed commercial forests undamaged by mining activities. The main disadvantage of forest restoration will always be a young forest age, which was one of the main factors influencing the recreational attractiveness of forests. The attractiveness of the Sokolov post-mining forests in the early (between 10 and 15 years) and middle (between 15 and 35 years) growth stages was very low, as uncovered in our results for spontaneous succession or by the literature on forest restoration with reclamation plantation forests [8]. We can expect a sharp increase in attractiveness in forests in a young growth stage (between 35 and 55 years) when there is no visible difference between the restored forests (replanted or spontaneously growing) and other commercial timber forests. The choice of restoration method-either forest reclamation or spontaneous succession-will not have any significant effect on forest attractiveness at the high forest age.

Ground unevenness created by dumping and the stratification of overburden material into 1-2 $\mathrm{m}$ high waves during the establishment and technical reclamation of spoil heap was an indisputable disadvantage for the attractiveness of young succession forests in the Sokolov post-mining area. On the other hand, these ground deformations provided a suitable habitat for the growth of succession tree species and other development of spontaneously emerging ecosystems $[38,39]$. These kinds of habitats were perceived as less safe, accessible, and maintained than forest reclamations of the same age. At the young growth stage, geophysical processes made these geomorphological irregularities less visible. Thus, this forest type was perceived to be more attractive than at its early growth stage. People perceived it as more natural and familiar; therefore, more attractive. 
Over the time horizon of 50 years or more, we can recommend the formation of a strongly deformed terrain when founding a spoil heap.

To improve the recreational attractiveness of forest reclamations created by the planting of a single target species on the Sokolov spoil heaps, it is important to increase permeability, stewardship, and safety by purposeful care. This is also true in the case of alder planting, motivated mainly by its suitability as a preparatory tree species. Our results implied that it is possible to improve numerous forest characteristics by appropriate silvicultural treatments at the same time since they are often correlated. In the case of the reclaimed forest stands, it is important to prune and thin out appropriately these forests at a young age; especially to realize a selective thinning of $30-40 \%$ of the basal area and the removal of deadwood, as recommended by [48].

\section{Conclusions}

This study investigated how various observable characteristics of forest stands afforested by different restoration procedures in post-mining areas affected their attractiveness for recreation. A mediation analysis of data from an online survey confirmed that post-mining forests growing on open-cast mine spoil heaps were perceived more negatively than conventional commercial spruce timber forests not affected by mining activities. The low attractiveness of restored forests can be attributed to their young growth stages, which was connected to their lower permeability and perceived low safety. A low level of perceived stewardship and lower familiarity can be attributed to mismanagement in the young growth stage of restored forest stands. Nevertheless, we observed differences in observable characteristics between various types of restoration procedures and tree species used for reclamation. While all observed characteristics changed by themselves with increasing age when considering restored sites with spontaneous succession, the improvement of replanted pine and especially replanted alder forests requires targeted after-care, combining thinning and pruning as common silvicultural practices used in young and middle-aged forest stands.

Supplementary Materials: The following are available online at https:/ /www.mdpi.com/article/10 .3390/land10090910/s1, Table S1: data set for structural equation models.

Author Contributions: J.M. and M.B.K. developed the conceptual ideas and supervised research activities. P.N., J.M. and M.B.K. designed the research methodology, conducted data analysis, and fitted the models. P.N. conducted a formal analysis. M.B.K. and J.M. performed the survey and collected data. P.N. supplied visualizations. P.N., M.B.K. and J.M. wrote the manuscript and contributed on to reviewing and editing it. J.M. was responsible for the funding acquisition and administration. All authors have read and agreed to the published version of the manuscript.

Funding: This research received funding from the Ministry of Agriculture of the Czech Republic (grant QK1710241—optimization of management of forest restoration on sites affected by surface mining).

Data Availability Statement: The data presented in this study are available in Supplementary Materials.

Conflicts of Interest: The authors declare no conflict of interest. The funders had no role in the design of the study; in the collection, analyses, or interpretation of data; in the writing of the manuscript, or in the decision to publish the results.

\section{Appendix A. Transcript of the Main Items of the Questionnaire}

Appendix A.1. Part 1: How Do You Perceive Forests?

First, take a close look at the following photos and try to realize how individual forests may look and how they may differ. 

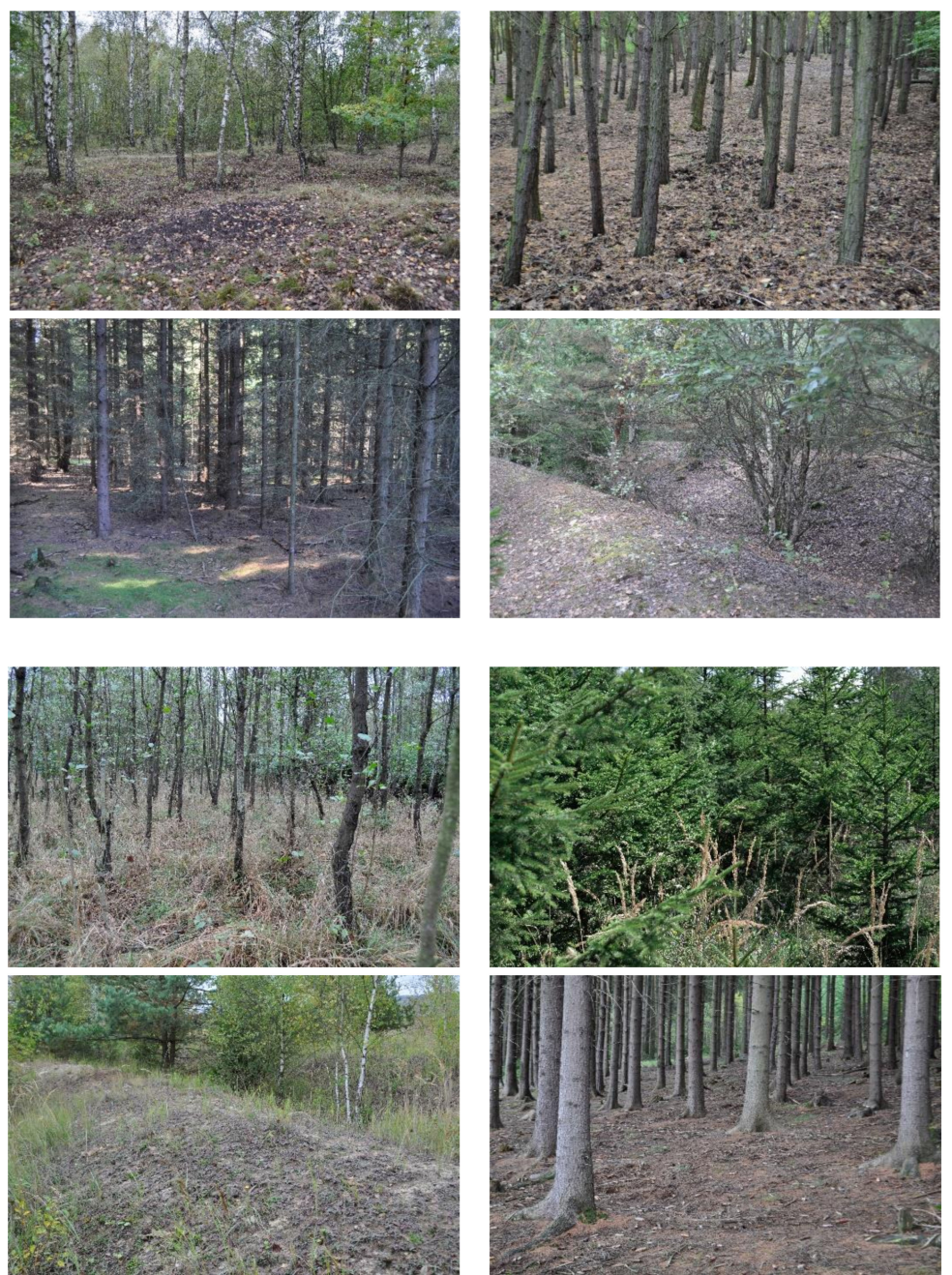

See four photos of this forest. The forest is characterized by various characteristics. We would like you to indicate how much different forests meet the individual characteristics.

For example, if you perceive the forest to be completely inaccessible, then mark the option -2 , or if quite accessible, then mark option -1 .

Forest n. 1
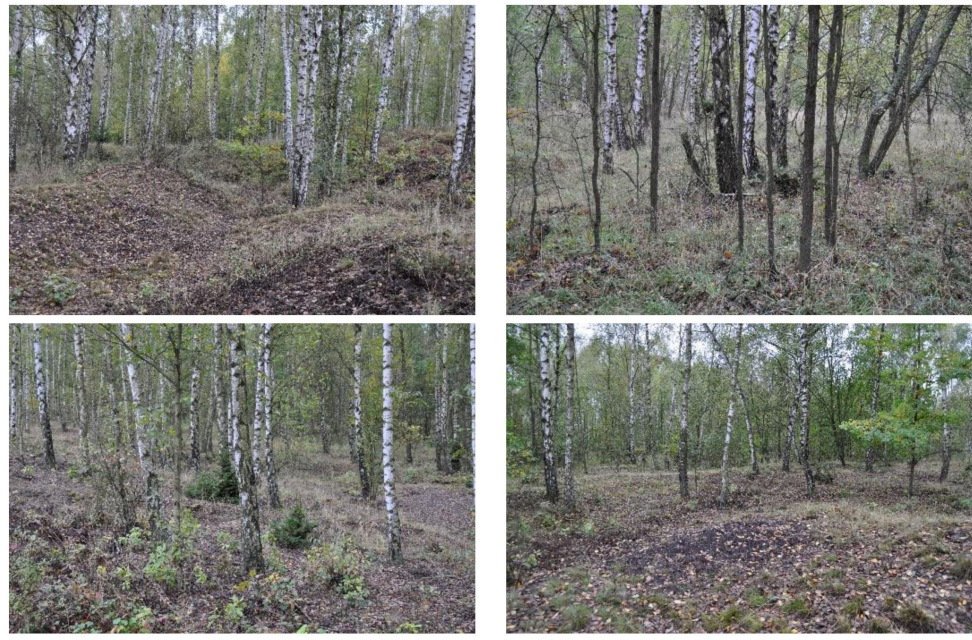

Try to state how much this forest meets the individual characteristics. 


$\begin{array}{rllllll}\text { Unnatural } & -2 & -1 & 0 & 1 & 2 & \text { Natural (close to the natural state) } \\ \text { Not maintained } & -2 & -1 & 0 & 1 & 2 & \text { Maintained } \\ \text { Inaccessible } & -2 & -1 & 0 & 1 & 2 & \text { Accessible } \\ \text { Not familiar to me } & -2 & -1 & 0 & 1 & 2 & \text { Familiar to me } \\ \text { Dangerous } & -2 & -1 & 0 & 1 & 2 & \text { Safe }\end{array}$

In a similar way, the 5-item question on the observed forest characteristics was repeated for another five forests.

\section{Appendix A.2. Part 2: Assessment of the Forest Sites}

Try to imagine yourself on a one sunny summer weekend day walking for one hour on a path surrounded by this forest.
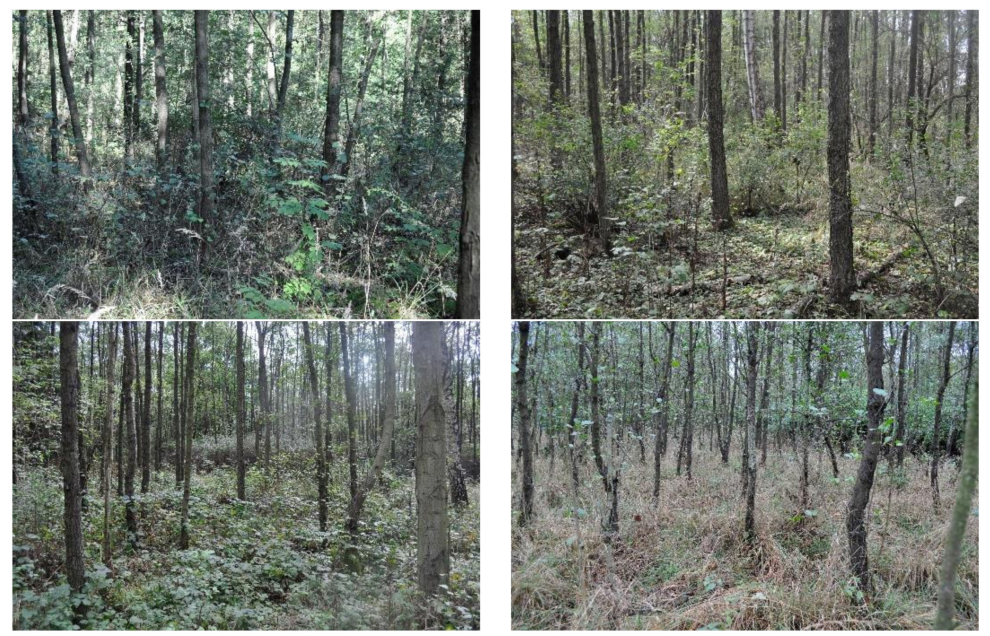

How tempting would it be for you to walk on a forest way in this forest for one hour?

$$
\begin{array}{lllllll}
\text { not at all } & -2 & -1 & 0 & 1 & 2 & \text { very tempting }
\end{array}
$$

In a similar way, the one-item question on the attractiveness of the forest for recreation was repeated for another five forests.

\section{References}

1. Han, K.-T. Responses to Six Major Terrestrial Biomes in Terms of Scenic Beauty, Preference, and Restorativeness. Environ. Behav. 2007, 39, 529-556. [CrossRef]

2. Ode, Å.; Fry, G.; Tveit, M.S.; Messager, P.; Miller, D. Indicators of Perceived Naturalness as Drivers of Landscape Preference. J. Environ. Manag. 2009, 90,375-383. [CrossRef]

3. Tveit, M.; Ode, Å.; Fry, G. Key Concepts in a Framework for Analysing Visual Landscape Character. Landsc. Res. 2006, 31, 229-255. [CrossRef]

4. Sharafatmandrad, M.; Khosravi Mashizi, A. Visual Value of Rangeland Landscapes: A Study Based on Structural Equation Modeling. Ecol. Eng. 2020, 146, 105742. [CrossRef]

5. Svobodova, K.; Sklenicka, P.; Molnarova, K.; Salek, M. Visual Preferences for Physical Attributes of Mining and Post-Mining Landscapes with Respect to the Sociodemographic Characteristics of Respondents. Ecol. Eng. 2012, 43, 34-44. [CrossRef]

6. Tyrväinen, L.; Silvennoinen, H.; Nousiainen, I. Combining Forestry and Nature-Based Tourism in Finland: An Analysis of Development Potentials and Constraints. In Proceedings of the IUFRO, Division 6 Social, Economic, Information and policy Sciences Meeting, Valdivia, Chile, 11-17 November 2002.

7. Alves Dias, P.; Kanellopoulos, K.; Medarac, H.; Kapetaki, Z.; Miranda-Barbosa, E.; Shortall, R.; Czako, V.; Telsnig, T.; VazquezHernandez, C.; Lacal Arántegui, R.; et al. EU Coal Regions: Opportunities and Challenges Ahead; EUR 29292 EN; Publications Office of the European Union: Luxembourg, 2018; ISBN 978-92-79-89884-6.

8. Braun Kohlová, M.; Máca, V.; Melichar, J.; Pavelčík, P. How High Is the Recreation Value of Successional Forests Growing Spontaneously on Coal Mine Spoil Heaps? Forests 2021, 12, 160. [CrossRef]

9. Gatersleben, B.; Andrews, M. When Walking in Nature Is Not Restorative-The Role of Prospect and Refuge. Health Place 2013, 20, 91-101. [CrossRef]

10. Ode, Å.; Tveit, M.S.; Fry, G. Capturing Landscape Visual Character Using Indicators: Touching Base with Landscape Aesthetic Theory. Landsc. Res. 2008, 33, 89-117. [CrossRef] 
11. Hoyle, H.; Jorgensen, A.; Hitchmough, J.D. What Determines How We See Nature? Perceptions of Naturalness in Designed Urban Green Spaces. People Nat. 2019, 1, 167-180. [CrossRef]

12. Edwards, D.; Jay, M.; Jensen, F.S.; Lucas, B.; Marzano, M.; Montagne, C.; Peace, A.; Weiss, G. Public preferences for structural attributes of forests: Towards a pan-European perspective. For. Policy Econ. 2012, 19, 12-19. [CrossRef]

13. Tyrväinen, L.; Silvennoinen, H.; Hallikainene, V. Effect of the season and forest management on the visual quality of the nature-based tourism environment: A case from Finnish Lapland. Scan. J. For. Res. 2017, 32, 349-359. [CrossRef]

14. Gobster, P.H.; Arnberger, A.; Schneider, I.E.; Floress, K.M.; Haines, A.L.; Dockry, M.J.; Benton, C. Restoring a "scenically challenged" landscape: Landowner preferences for pine barrens treatment practices. Landsc. Urban Plan. 2021, $211,104104$. [CrossRef]

15. Edwards, D.; Jay, M.; Jensen, F.S.; Lucas, B.; Marzano, M.; Montagné, C.; Peace, A.; Weiss, G. Public Preferences across Europe for Different Forest Stand Types as Sites for Recreation. Ecol. Soc. 2012, 17. [CrossRef]

16. Ribe, R.G. Perceptions of forestry alternatives in the US Pacific Northwest: Information effects and acceptability distribution analysis. J. Environ. Psychol. 2006, 26, 100-115. [CrossRef]

17. Gundersen, V.; Clarke, N.; Dramstad, W.; Fjellstad, W. Effects of bioenergy extraction on visual preferences in boreal forests: A review of surveys from Finland, Sweden and Norway. Scand. J. For. Res. 2016, 31, 323-334. [CrossRef]

18. Gundersen, V.; Frivold, L.H. Naturally dead and downed wood in Norwegian boreal forests: Public preferences and the effect of information. Scand. J. For. Res. 2010, 26, 110-119. [CrossRef]

19. Gundersen, V.; Stange, E.E.; Kaltenborn, B.P.; Vistad, O.I. Public visual preferences for dead wood in natural boreal forests: The effects of added information. Landsc. Urban Plan. 2017, 158, 12-24. [CrossRef]

20. Janeczko, E.; Bielinis, E.; Tiarasari, U.; Woźnicka, M.; Kędziora, W.; Przygodzki, S.; Janeczko, K. How Dead Wood in the Forest Decreases Relaxation? The Effects of Viewing of Dead Wood in the Forest Environment on Psychological Responses of Young Adults. Forests 2021, 12, 871. [CrossRef]

21. Stamps, A.E. Demographic Effects in Environmental Aesthetics: A Meta-Analysis. J. Plan. Lit. 1999, 14, 155-175. [CrossRef]

22. Silvennoinen, H.; Alho, J.; Kolehmainen, O.; Pukkala, T. Prediction models of landscape preferences at the forest stand level. Landsc. Urban Plan. 2001, 56, 11-20. [CrossRef]

23. Van den Berg, A.E.; Vlek, C.A.J.; Coeterier, J.F. Group differences in the aesthetic evaluation of nature development plans: A multilevel approach. J. Environ. Psychol. 1998, 18, 141-157. [CrossRef]

24. Liu, X.; Tvinnereim, E.; Grimsrud, K.M.; Lindhjem, H.; Velle, L.G.; Saure, H.I.; Lee, H. Explaining landscape preference heterogeneity using machine learning-based survey analysis. Landsc. Res. 2021, 46, 417-434. [CrossRef]

25. Ribe, R.G. Is Scenic Beauty a Proxy for Acceptable Management?: The Influence of Environmental Attitudes on Landscape Perceptions. Environ. Behav. 2002, 34, 757-780. [CrossRef]

26. Ford, R.M.; Williams, K.J.H.; Smith, E.L.; Bishop, I.D. Beauty, Belief, and Trust: Toward a Model of Psychological Processes in Public Acceptance of Forest Management. Environ. Behav. 2014, 46, 476-506. [CrossRef]

27. Tolvanen, A.; Kangas, K.; Tarvainen, O.; Huhta, E.; Jäkäläniemi, A.; Kyttä, M.; Nikula, A.; Nivala, V.; Tuulentie, S.; Tyrväinen, L. The relationship between people's activities and values with the protection level and biodiversity. Tour. Manag. 2020, 81, 104141. [CrossRef]

28. Hartig, T.; Staats, H. The need for psychological restoration as a determinant of environmental preferences. J. Environ. Psychol. 2006, 26, 215-226. [CrossRef]

29. Arnberger, A.; Eder, R. The Influence of Green Space on Community Attachment of Urban and Suburban Residents. Urban For. Urban Green. 2012, 11, 41-49. [CrossRef]

30. Fry, G.; Tveit, M.S.; Ode, Å.; Velarde, M.D. The Ecology of Visual Landscapes: Exploring the Conceptual Common Ground of Visual and Ecological Landscape Indicators. Ecol. Indic. 2009, 9, 933-947. [CrossRef]

31. Lis, A.; Pardela, Ł.; Can, W.; Katlapa, A.; Rabalski, Ł. Perceived Danger and Landscape Preferences of Walking Paths with Trees and Shrubs by Women. Sustainability 2019, 11, 4565. [CrossRef]

32. Chiang, Y.-C.; Nasar, J.L.; Ko, C.-C. Influence of Visibility and Situational Threats on Forest Trail Evaluations. Landsc. Urban Plan. 2014, 125, 166-173. [CrossRef]

33. Sonti, N.F.; Campbell, L.K.; Svendsen, E.S.; Johnson, M.L.; Novem Auyeung, D.S. Fear and Fascination: Use and Perceptions of New York City's Forests, Wetlands, and Landscaped Park Areas. Urban For. Urban Green. 2020, 49, 126601. [CrossRef]

34. Kaplan, R.; Kaplan, S. The Experience of Nature: A Psychological Perspective; Cambridge University Press: Cambridge, UK; New York, NY, USA, 1989; ISBN 0-521-34139-6.

35. Pedersen, D.M. Relationship between environmental familiarity and environmental preference. Percept. Mot. Ski. 1978, 47, 739-774. [CrossRef]

36. Imamoglu, Ç. Complexity, liking and familiarity: Architecture and non-architecture Turkish students' assessments of traditional and modern house facades. J. Environ. Psychol. 2000, 20, 5-16. [CrossRef]

37. Ministry of Agriculture. Information on Forests and Forestry in the Czech Republic by 2019; Ministry of Agriculture of the Czech Republic: Prague, Czech, 2020; ISBN 978-80-7434-571-5.

38. Frouz, J.; Pižl, V.; Cienciala, E.; Kalčík, J. Carbon storage in post-mining forest soil, the role of tree biomass and soil bioturbation. Biogeochemistry 2009, 94, 111-121. [CrossRef] 
39. Mudrák, O.; Frouz, J.; Velichová, V. Understory vegetation in reclaimed and unreclaimed post-mining forest stands. Ecol. Eng. 2010, 36, 783-790. [CrossRef]

40. Bryman, A. Social Research Methods, 4th ed.; Oxford University Press: New York, NY, USA, 2012.

41. Edwards, J.R.; Lambert, L.S. Methods for integrating moderation and mediation: A general analytical framework using moderated path analysis. Psychol. Methods 2007, 12, 1-22. [CrossRef]

42. Rosseel, Y. Lavaan: An R Package for Structural Equation Modeling. J. Stat. Softw. 2012, 48, 1-36. [CrossRef]

43. Baron, R.M.; Kenny, D.A. The moderator-mediator variable distinction in social psychological research: Conceptual, strategic, and statistical considerations. J. Personal. Soc. Psychol. 1986, 56, 1173-1182. [CrossRef]

44. Celli, V. Causal mediation analysis in economics: Objectives, assumptions, models. J. Econ. Surv. 2021. [CrossRef]

45. Collado, S.; Staats, H.; Sorrel, M.A. A relational model of perceived restorativeness: Intertwined effects of obligations, familiarity, security and parental supervision. J. Environ. Psychol. 2016, 48, 24-32. [CrossRef]

46. Schulz, C.; Martin-Ortega, J.; Glenk, K. Value landscapes and their impact on public water policy preferences. Glob. Environ. Chang. 2018, 53, 209-224. [CrossRef]

47. Ryan, J. Plants as objects: Challenges for an aesthetics of flora. Philos. Stud. 2011, 1, 222-236.

48. Paletto, A.; Guerrini, S.; De Meo, I. Exploring visitors' perceptions of silvicultural treatments to increase the destination attractiveness of peri-urban forests: A case study in Tuscany Region (Italy). Urban For. Urban Green. 2017, 27, 314-323. [CrossRef] 